\title{
GIS Processing of Large-scale Soil Maps in Hungary
}

\author{
L. PÁSZTOR, J. SZABÓ and ZS. BAKACSI \\ Research Institute for Soil Science and Agricultural Chemistry (RISSAC) of the \\ Hungarian Academy of Sciences, Budapest
}

The concept of sustainable development, the demand for environment protection and Hungary's expected EU accession brings soil-related information into focus. Hungarian agriculture, rural and regional development should also be supported by GIS technology already used in the EU (http://europa.eu.int/ comm/agriculture/index_en.htm). For the delineation of concrete functions, it is indispensable to elaborate a standard, spatially based, integrated information system. The demand for information is growing parallel with the rapid expansion of informatics tools and methods. At the same time, access and interpretation of existing data and information are problem areas. The Ministry of Agriculture - with the aim of promoting Hungary's EU accession - laid down the basis of the agro-environment management program in the late nineties (http://www.fvm.hu/agrar.pdf). The coordinating institutional network of the regional development programs requires the establishment of map-based databases (NÉMETH et al., 2000).

A great amount of soil information is available in Hungary due to previous agrogeological surveys (VÁRALLYAY, 1989). The collected data are available in different scales: national, regional, micro-regional, farm and field level and they are generally related to maps. In the 1990's a great part of these soil data was organized into geographic soil information systems by the RISSAC GIS Lab. At the beginning small-scale $(1: 100,000-1: 5,000,000)$ systems were elaborated (Agrotopo: VÁRALlyAY \& MOLNÁR, 1989; HunSOTER: VÁRALLYAY et al., 1994; MERA: SZABÓ et al., 1998; SOVEUR: VÁRALLYAY et al., 2000). Recently we have been concentrating on the more challenging large-scale systems.

The agricultural land redistribution and privatization process in Hungary in the early 90's induced a transformation process in co-operatives. The over-large co-operative farms separated to form smaller, more localized enterprises and converted into other company forms. However, no special privileges are given to them and they should be able to stand competition. Concerning these chal-

Correspondence to: Dr. László PÁSZTOR, Research Institute for Soil Science and Agricultural Chemistry (RISSAC) of the Hungarian Academy of Sciences, H-1022 Budapest, Herman Ottó út 15. Hungary. E-mail: pasztor@rissac.hu 
lenges some co-operative farms initiated the introduction of up-to-date methods in their agricultural practice: computerization, collection of relevant data on the farming units, introduction of information and expert systems, compilation of farm-scale integrated geographical information systems.

Site-specific management - unlike general agricultural practice - does not treat management units as homogeneous plots. Precision agriculture requires three main components: accurate positioning (based on GPS), real-time technology for controlling agrotechniques and appropriate spatial databases that provide information necessary to obtain the promised benefits of precision agriculture (CAMBARDELLA \& KARLEN, 1999). In this context soil represents one of the most important factors involved, and the larger the applied scale the more accurate the achieved result. For site-specific management the relevant mapequivalent scale of spatial information is at least 1:10,000. Larger scale based data could provide better results but are seldom available. It is partly large-scale spatial soil information systems that has made the evolution of precision agriculture possible.

Agricultural advisory and recommendation systems summarize current knowledge on soil fertility, nutrient supply and limiting factors with respect to the expected yield. In Hungary in the ' 70 s a systematic program was introduced for controlling the plant nutrient status of cultivated soils. In the ' $80 \mathrm{~s}$ a new computerized fertilizer system was elaborated (VÁRALLYAY et al., 1992), which was used on more than 500,000 ha. After the political and economical changes in the late ' 80 s-early ' $90 \mathrm{~s}$, which had drastic influence on Hungarian agriculture, a demand rose for a new, cost saving, environment-friendly fertilizer recommendation system (CSATHÓ et al., 1998). The next step in the improvement of these advisory and recommendation systems should be the extension of their spatial features, that is integrating them with GIS.

People have used maps for thousands of years to clearly present information about places, and GIS is a modern extension of that ancient tradition. A Geographical Information System is a tool that uses the power of the computer to pose and answer geographic questions by arranging and displaying data about places in a variety of ways, such as maps, charts, and tables. GI systems are designed for storing, querying, analyzing as well as for displaying data and/or information with spatial characteristics (MAGUIRE, 1991). GIS represents both the techniques to realize manageable storage of spatial data and extended opportunities of spatial analysis on the stored data. Recently, this latter is getting more and more attention to facilitate the computerized, spatial modelling of the geographical environment (LONGLEY et al., 1999). The spreading of these systems has brought with it the development of their theory and, on the other hand, their everyday usage induced the extension of their service functions. GIS, originally the abbreviation of Geographic Information System, is recently known as Geographic Information Science (LONGLEY et al., 2001) and is also becoming Geographic Information Service (DANGERMOND, 2001). 


\section{Materials and Methods}

Presently mainly ESRI (Environment System Research Institute; www.esri. com) products are used in the compilation, manipulation and display of geocoded, soil related datasets in the RISSAC GIS Lab (PC ARC/INFO 3.5, ARC/ INFO 8.1, ArcView 3.2). For complex spatial queries and analysis Spatial Analyst and 3D Analyst modules are applied, images are managed by Image Analysis module. For customizing the available toolset as well as to solve newly emerged spatial problems Avenue scripts are developed using ArcView's object oriented developing language.

\section{The Kreybig 1:25,000 scale practical soil mapping.}

The national soil-mapping project initiated and led by L. Kreybig (KREYBIG, 1937) was unique in being a national, large-scale survey based on field and laboratory soil analysis, and at the same time serving practical purposes. The aim of the programme was the preparation of a map series from which those soil properties could be defined directly, which show the physiological conditions of the organisms living in soil and the cultivated plants. The Kreybig maps are still timely, because the temporal changes in the mapped soil characteristics are not significant. This statement is mainly valid for the soil pattern provided by the original maps.

The soil and land use conditions were shown jointly on the detailed soil maps. Land use conditions were given in a simplified form, distinguishing: croplands, temporarily waterlogged areas, forests, lakes, marshes, rivers and settlements. The soil patches were deliniated based on their chemical and physical soil properties. The characteristic of the Kreybig method is that, a representative and further, non-representative soil profiles occurring within the patch are attached to the soil unit of the map. These profiles jointly give information on the heterogeneity of the area.

The processing level of the presently available information collected during the Kreybig-lead survey, the scale and „mapping quality” differs from sheet to sheet. The various archives include map sheets on different processing level (survey sheets, actually the mounted topographic maps; original sheets which are also topographic maps edited on the basis of the former and prepared in single copy; hand-painted map sheets prepared in at least 5 copies; printed map sheets prepared in 100 copies and overlaid on gray scale topographical background.). There are also differences in the scale of the soil maps as well as the used projection system (stereographic, cylindrical). Generally the actual scale is $1: 25,000$, but in some cases only 1:50,000 or 1:75,000 scale sheets exist. In the worst case there is no existing Kreybig map at all for a given region, which often occurs along the country border. 
GIS processing of the Kreybig archives started in 1998 at RISSAC GIS Lab (SZABÓ et al., 2000). The mainly self-financed experimental project endeavours to elaborate a self-consistent, map based, digital, spatial soil information system integrating the Kreybig data available at various institutions, in different scale and processing level. During this work we also rely on more recent soil information and various digitally available geographic information sources which can be used in the reambulation process.

The research development carried out so far by RISSAC GIS Lab includes the digital archivation of the maps (scanning), transformation into the Hungarian Unified Map Projection System (HUMPS), the determination of the logical data model of the Information System, planning of input/output processes, development of the database and spatial elements, data compilation for different sample areas. The basic version of the structured system design was elaborated, and pilot systems were established in different areas of the country.

\section{The 1:10,000 scale practical soil surveys}

In the early 60's a large-scale soil survey system was elaborated by Hungarian soil scientists, soil surveyors and soil mapping specialists to satisfy the soil information practical needs of the large farming units (state and cooperative farms) characteristic of Hungarian agriculture between 1950 and 1990. Such maps were prepared for about $1 / 3$ of Hungary's area $\left(\sim 35,000 \mathrm{~km}^{2}\right)$. The system consists of four main parts: 1 . genetic soil map, indicating soil taxonomy units, and the parent material; 2 . thematic soil maps on the most important physical and chemical soil properties; 3. thematic maps, indicating recommendations for rational land use, cropping pattern, amelioration, tillage practice and fertilization; 4. explanatory booklets, including a short review on the physiographical conditions; description of soils, recommendations for their rational utilization; field description of soil profiles; results of field observations or measurements and data of laboratory analyses (SARKADI et al., 1964; SZABOLCS, 1966; SARKADI \& VÁRALLYAY, 1989). These maps were used widely and successfully in Hungary and became an easily applicable scientific basis of intensive, large-scale agricultural production in spite of the fact that generally these maps were not published in printed form and are available only as manuscripts at the given farming units or at the Plant and Soil Conservation Stations. The large-scale soil mapping programme restarted in 1986 within the framework of the National Land Evaluation Programme (Guidelines ..., 1987). The aim of this Programme was to evaluate the agricultural land based on soil information surveyed in a scale of 1:10,000, but has not been completed.

These huge archives provide appropriate raw material for recent digitally based applications. Spatial soil information systems based on these data could be efficiently used in the cases listed in the introduction. 


\section{Results and Discussion}

\section{The Kreybig Digital Soil Information System}

The compilation of the Kreybig Digital Soil Information System (KDSIS) has been going on step by step on smaller and larger sample areas. Data processing is carried out by map sheets. Having completed the geometric and thematic digitization of neighbouring sheets they are fitted together solving edge correction, then they are merged. At the same time primary reambulation is carried out by taking into consideration the changes reflected by digitally available recent information on topography and/or land use (remotely sensed images, spatial databases), which are simultaneously used within the same GIS environment. A secondary, thematic reambulation of the database seems to be necessary too, which needs extra-institutional co-operation.

The digital processing of the different spatial entities of Kreybig maps (the polygon type soil units and the point type soil profiles) and loading of profile database progresses independently. At present the compilation of the spatial pattern (i.e.: polygon structure of soil patches) of KDSIS has been completed for about $40 \%$ of the country (Figure 1). Compilation of the profile database module is a bit lagging behind. The spatial pattern provided by the soil polygons together with their features, however, are suitable for various applications by themselves.

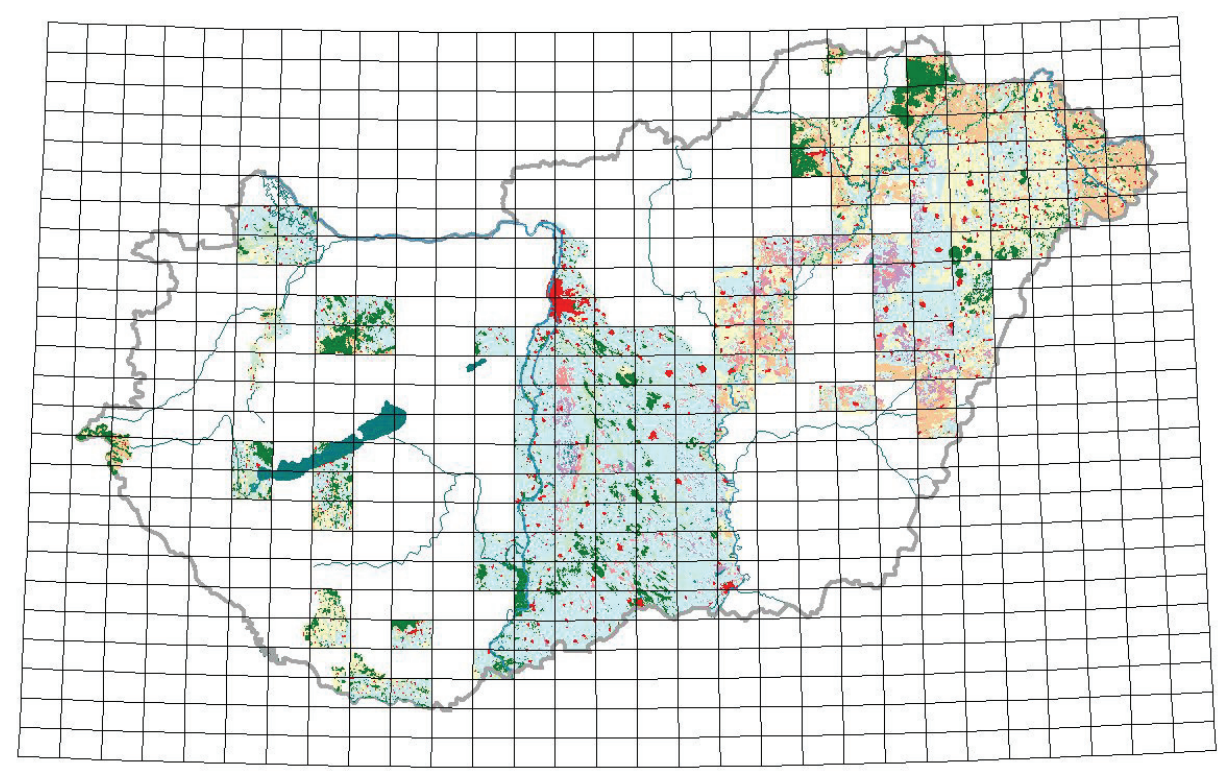

Figure 1

The spatial pattern provided by KDSIS according to its most recent state 
The GIS-based manipulation of KDSIS makes the solution of various problems possible. First of all the possibility in substituting missing map sheets should be emphasized. As mentioned above, there are some uncovered regions where Kreybig map sheets are not available in any kind of processing phase. Integrating knowledge on the spatial pattern of soil originating from existing, neighbouring map sheets with existing land use and/or topographical digital coverages referring to the given area can result in half recreated, half restored soil patches - keeping the Kreybig mapping philosophy in mind.

The GIS environment also gives opportunity for the refinement of soil pattern provided by the original survey. Either the original soil profiles (knowing their actual spatial position) or newly dug ones can be used for the subdivision of existing mapping units, taking digitally available supplementary environmental/geographical spatial information into consideration.

The fully loaded KDSIS can serve as a well-established basis for various soil related expert systems. Some key soil characteristics were already derived for pilot areas where the system was completed. Genetic soil type according to the Hungarian national classification system and soil bonitation value applicable for land evaluation was obtained for some sample areas.

\section{Farm-scale GI systems}

During the second half of the "90s RISSAC GIS Lab was commissioned to carry out GIS adaptation of practical soil maps created for the territory of some of the newly formed agricultural companies. At the beginning this only meant digitization of the current map sheets. Later new demands emerged and the digitized soil maps were transformed into HUMPS. This operation opened the opportunity to integrate soil information with additional environmental, topographic spatial data available or newly processed digitally in compatible scale. This also made a more precise spatial determination and delineation of actual management units possible. Usage of up-to-date remotely sensed images also helped by revealing some changes in land use. As a next step multitemporal data of the management unit registers were linked to their geometrical representation and thus jointly used with other geographical, agri-environmental spatial information. Simply spatial advisory systems were elaborated.

There was an initiative in RISSAC for the integration of three fields of research to elaborate a GIS-based precision fertilization recommendation system (CZINEGE et al., 1999). The within-plot soil inhomogeneities were taken into account, as their fertility potential generally differs. Thus, in this system the amount of fertilizer is applied according to the average feature of soil units. The method provides improvement as compared to recent Hungarian agricultural practice, if there are several soil types within one management unit. For the detailed elaboration of our objectives, we chose two sample areas in the central part of Hungary with different geographical characteristics. Integrated spatial 
soil information databases were developed for the pilot areas based on practical soil mappings and 1:10,000 scale topographic and cadastre maps. The resulted system provided maps, which were used for planning the sampling design as well as the basis for the compilation of fertilization recommendation plans.

After the above-mentioned early initiatives a complex system was elaborated by RISSAC GIS Lab in close co-operation with the Plant and Soil Conservation Service of Fejér County for the whole territory (about 3,500 ha) of a co-operative farm in Central Hungary. In addition to carrying out the digital reambulation and GIS adaptation of large-scale soil mappings further information was integrated into the system: 1. topographic data, ensuring the delineation of the geographical environment and helping information processing and positioning; including a DEM; 2. property register data determining the ownership and registration conditions of parcels; 3 . multitemporal data of nutrient control based fertilization advisory system monitored yearly. The elaborated complex system is structured as follows:

Uniform topography and terrain data: raster images of the 1:10,000 scale topographic maps transformed into HUMPS; digital elevation model (DEM: grid cell size is $10 \times 10 \mathrm{~m}$ ) and its derivatives (exposure of slopes, and slope gradient); 1:10,000 scale basic topographic data (main roads, waterways, railway lines), and the boundaries of built-up areas.

Data of complex property register: Raster images of the 1:10,000 scale generalized cadastre maps of outskirts for the territory of the concerned villages transformed into HUMPS; geo-coding of the complex property register (cadastre) represented by points, which are located on the center of the parcel; property register containing data on parcels, plots and sub-classes grouped according to settlements and terrain; borders of management units as they can be identified using 1:10,000 scale generalized cadastre maps of outskirts; corner points of parcels and plots based on County Land Office register.

Soil data: Relevant segment of the 1:25,000 scale DKSIS; data of the 1:10,000 scale practical soil mappings (genetic soil map, indicating soil taxonomy units, and the parent material; thematic soil maps on the most important physical and chemical soil properties; and thematic maps, indicating recommendations for rational land use, cropping pattern, amelioration, tillage practice and fertilization); data of explanatory booklets including results of field observations together with the measurements and data of laboratory analyses.

Time series provided by the nutrient control based fertilization advisory system monitored yearly which includes digital, tabulated data on: nutrient supply; micro- and macroelements; heavy metal contamination; yield attributed to management units.

The elaborated information system provides a wide palette of outputs: simple maps reproducing thematic cartograms, new maps derived from base elements, results of spatial queries and analysis carried out with optional combination of point, polygon and tabular data (Figure 2). The system was com- 


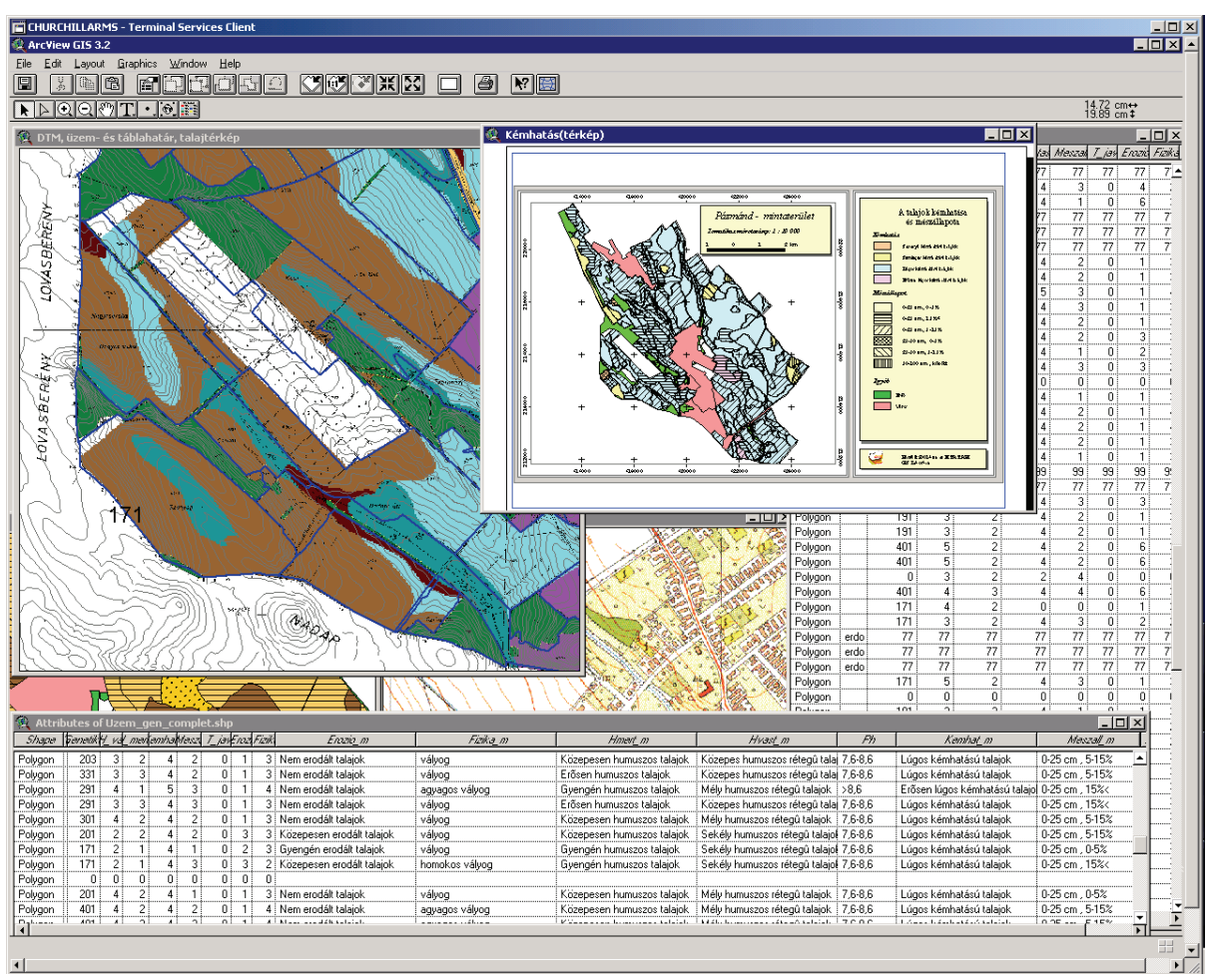

Figure 2

The GIS user interface of the elaborated complex system indicating some basic elements (tables, working surfaces, digital maps compiled for hardcopy)

pleted in 2001. As a next step an Intranet/Internet based realization of the system has been worked out. This type of user interface can be learnt and used by anyone and can provide fast access to the spatial data and operates system independent. Internet also provides other useful advantages, as Internet browsers are available almost everywhere and this technology provides access to the server for an unlimited number of users.

\section{Conclusion}

The Kreybig-led survey as well as the 1:10,000 scale practical soil surveys provided exceptionally valuable soil information for the whole country or for a significant part of the country's agricultural lands, respectively. These are still appropriate data sources for soil-related applications, while detailed soil information is just coming into focus due to recent environmental, agricultural, economical, political and social challenges. 
Although the availability, the processing level, the scale and the mapping quality of the information collected during these mapping projects are very inhomogeneous, GIS adaptation and digital reambulation can be carried out, according to our experiences and achievements, making the elaboration of mapbased, digital, large scale spatial soil information systems possible.

The applicability of the systems compiled up till now is simply proven by the fact that their users were satisfied by the raw or value added data queried from these systems, maps produced based on them or the result achieved by their spatial analysis. Advisory and recommendation systems as well as sitespecific management practices can rely on these systems in the future.

In case of suitable state financing, the partial construction of the KDSIS should be followed by the completition and thematic reambulance of the database, which requires the cooperation of county Plant Health and Soil Conservation Services and research institutes.

State financing for the construction of farm-scale digital soil information systems is expectable because of the requirements set up for Hungary's EU accession. Soil scientific and GIS staff of the county Plant and Soil Conservation Services and the experts of research institutes could provide the suitable personnel background for such activities.

\section{Summary}

GIS adaptation and digital reambulation of large-scale soil information originating from various agrogeological surveys has become a key issue in Hungary due the recent challenges. The national programme initiated by L. Kreybig for the systematic, 1:25,000 scale practical soil mapping of Hungary was carried out between 1935 and 1951, and provided detailed soil information (1:25,000 scale maps and complementary database in the form of explanatory booklets) for the whole country. Later farm level (1:10,000 scale) soil surveys fulfilled the practical requirements of Hungarian agriculture, producing a huge quantity of map based, soil related data. These archives still represent a valuable treasure of soil information at present. Their digital reambulation and GIS adaptation is a challenging task, which was initiated by RISSAC GIS Lab in co-operation with various institutions. The aim of these activities is the development of large-scale soil modules of a Hungarian production database for the determination of the optimal functions of agriculture in a given region, together with the harmonization of agricultural production and the protection of land and environment.

Key words: soil information system, reambulation, farm scale, micro-region scale

Present work was partly funded by the Hungarian National Research Fund (OTKA) (Grant Nos. T033003 and F021232). 


\section{References}

Cambardella, C. A., \& Karlen, D. L., 1999. Spatial analysis of soil fertility parameters. Precision Agriculture. 1. (1) 5-14.

CSATHÓ, P., ÁRENDÁS, T. \& NÉMETH, T., 1998. New environmentally friendly fertiliser advisory system, based on the data set of the Hungarian long-term field trials set up between 1960 and 1995. Soil Sci. Plant Anal. 29. 2161-2174.

CZINEGE E. et al., 1999. Elaboration of a farm level, GIS based fertilizer advisory system in Hungary. In: Precision Agriculture '99, Part 2. (Ed.: STAFFORD, J. V.) 969975. Academic Press. Sheffield.

DANGERMOND, J., 2001, 'g.net - A New GIS Architecture for Geographic Information Service. ArcNews. 23. (1)

Guidelines to Large-scale Soil Mapping, 1987. (In Hungarian) Melioráció, Öntözés és Tápanyaggazdálkodás. Agroinform. Budapest.

KREYBIG, L., 1937. The survey, analytical and mapping method of the Hungarian Royal Institute of Geology. (In Hungarian). M. Kir. Földtani Int. Évkönyve. 31. 147-244.

LONGLEY, P. A. et al. (Eds.) 1999. Geographical Information Systems, Principles and Technical Issues. Wiley. London.

LONGLEY, P. A. et al. (Eds.) 2001. Geographic Information Systems and Science. Wiley. London.

Maguire, D. J., 1991. Geographical Information Systems: Principles and Application. Longman. London.

NÉMETH, T. et al., 2000. Role of small and large scale soil information in the National Agroenvironmental Program. (In Hungarian) Talajvédelem. 8. (3-4) 53-60.

SARKADI, J. \& VÁrallyaY, GY., 1989. Advisory system for mineral fertilization based on large-scale landsite maps. Agrokémia és Talajtan. 38. 775-789.

SARKADI, J., SzŰCS, L. \& VÁRAllyay, GY., 1964, Large-scale Genetic Soil Maps (In Hungarian). OMMI Genetikus Talajtérképek. Ser. 1. No. 8. Budapest.

SZABÓ, J. et al., 1998. Integration of remote sensing and GIS techniques in land degradation mapping. Agrokémia és Talajtan. 47. 63-75.

SzABÓ, J. et al., 2000. Kreybig Digital Soil Information System (Preliminaries, GIS establishment). (In Hungarian) Agrokémia és Talajtan. 49. 265-276.

SZABOLCS, I. (Ed.), 1966. The Handbook of the Large-scale Genetic Soil Mapping. (In Hungarian). OMMI Genetikus Talajtérképek. Ser. 1. No. 9. Budapest.

VÁRAllyay, GY., 1989. Soil mapping in Hungary. Agrokémia és Talajtan. 38. 696714.

VÁRALLYAY, GY. \& MOLNÁR, S., 1989. The agro-topographical map of Hungary. Hungarian Cartographical Studies. 14th World Conf. ICA-ACI. 221-225. Budapest.

VÁRALlYAY, GY. et al., 1992, New plant nutrition advisory system in Hungary. Soil Sci. Plant Anal. 23. 2053-2073.

VÁRALlYAY, GY. et al., 1994. SOTER (Soil and Terrain Digital Database) 1:500,000 and its application in Hungary. Agrokémia és Talajtan. 43. 87-108.

VÁRALLYAY, GY. et al., 2000. Country report on the activities and main results of the SOVEUR Project. In: Soil and Terrain Database, Land Degradation Status and Soil Vulnerability Assessment for Central and Eastern Europe (Eds.: BATJES, N. H. \& BRIDGES, E. M.) FAO Land and Water Digital Media Series 10. CD-ROM, FAO. Rome. 